\title{
Calcium/calmodulin-dependent protein kinase II enhances metastasis of human gastric cancer by upregulating nuclear factor- $\kappa B$ and Akt-mediated matrix metalloproteinase-9 production
}

\author{
ZHAOLONG LIU, GANG HAN, YU CAO, YIDONG WANG and HANGJUN GONG \\ Department of General Surgery, Shuguang Hospital Affiliated to Shanghai University of Traditional Chinese Medicine, \\ Shanghai 201203, P.R. China
}

Received December 5, 2013; Accepted May 23, 2014

DOI: $10.3892 / \mathrm{mmr} .2014 .2525$

\begin{abstract}
Calcium/calmodulin-dependent protein kinase II (CaMKII) is a multi-functional serine/threonine protein kinase, involved in processes that cause tumor progression, including cell cycle regulation, apoptosis and differentiation. However, the role of CaMKII in cancer cell metastasis has not been fully elucidated. In the present study, the function of CaMKII in gastric cancer cell metastasis is reported. Firstly, it was demonstrated that the overexpression of H282R (constitutively active CaMKII) enhanced gastric cancer cell migration and invasion, and the inhibition of CaMKII activity by KN-62 decreased gastric cancer cell metastasis. Furthermore, H282R upregulated matrix metalloproteinase-9 (MMP-9) expression and production, which were dependent on CaMKII-mediated increase in nuclear factor (NF)- $\kappa \mathrm{B}$ and Akt activation. Finally, CaMKII activation, through phosphorylation of the Thr 286 site, was significantly increased in the metastatic gastric cancer tissues compared with non-metastatic tissues, suggesting that CaMKII has an important function in the regulation of gastric cancer cell metastasis. Collectively, the present study demonstrated that CaMKII promotes gastric cancer cell metastasis by $\mathrm{NF}-\kappa \mathrm{B}$ and Akt-mediated-MMP-9 production. These findings suggest a novel function of CaMKII in the control of gastric
\end{abstract}

Correspondence to: Dr Hangjun Gong, Department of General Surgery, Shuguang Hospital Affiliated to Shanghai University of Traditional Chinese Medicine, 528 Zhangheng Lu, Shanghai 201203, P.R. China

Email: gonghjshuguang@126.com

Abbreviations: CaMKII, calcium/calmodulin-dependent protein kinase II; MAPK, mitogen-activated protein kinase; $\mathrm{NF}-\kappa \mathrm{B}$, nuclear factor- $\kappa \mathrm{B}$; MMP, matrix metalloproteinase; MTT, 3-(4,5-dimethylthiazol-2-yl)-2,5-diphenyltetrazolium bromide

Key words: calcium/calmodulin-dependent protein kinase I, gastric cancer metastasis, matrix metalloproteinase-9, nuclear factor- $\kappa \mathrm{B}$, Akt cancer metastasis, offering a promising target for future therapeutics to treat and prevent gastric cancer metastases via the inhibition of CaMKII activity.

\section{Introduction}

Gastric cancer is the fourth most common type of cancer and the second leading cause of cancer-associated mortality worldwide (1). Cancer metastasis is the leading cause of cancer treatment failure and is chiefly responsible for the poor prognosis of patients with gastric cancer (2). The biological mechanisms of metastasis appear to involve a complex array of genetic alterations, including changes in the expression of adhesion molecules (such as, integrins and cadherins), proteolytic enzymes (such as, matrix metalloproteinases) and signaling pathway components [such as, mitogen-activated protein kinase (MAPK) and Akt] (3). However, the molecular mechanisms involved in gastric cancer remain unclear. Therefore, examining the biological mechanisms underlying gastric cancer metastasis and developing a novel effective therapeutic target for gastric cancer treatment remains critical.

Calcium/calmodulin-dependent protein kinase II (CaMKII) is a multifunctional serine/threonine protein kinase with wide distribution and multiple substrates in mammalian cells $(4,5)$. CaMKII is composed of a combination of four enzyme isoforms $(\alpha, \beta, \gamma$ or $\delta)$, and each subunit contains a catalytic domain, a regulatory domain (including an auto-inhibitory region) and a calmodulin-binding region (6). In resting cells, CaMKII is a dodecameric holoenzyme that auto-inhibits catalytic activity via the auto-inhibitory domain. Binding of calcium/calmodulin to CaMKII relieves its auto-inhibition, resulting in $\mathrm{Ca}^{2+}$-independent CaMKII activation and phosphorylation of the Thr 286 site to sustain CaMKII activity (7). CaMKII inhibitors have been used to investigate CaMKII function, specifically several CaMKII inhibitors (including chemically synthesized KN-62 and KN-93) and endogenous inhibitory proteins (e.g. CaMKIIN $\alpha$ and CaMKIIN $\beta$ derived from humans and mice). KN-62 and KN-93 inhibit CaMKII phosphorylation by interfering with calcium/calmodulin binding $(8,9)$, thereby suppressing CaMKII activity. Endogenous inhibitory proteins CaMKIINa 
and CaMKIIN $\beta$ interact with activated CaMKII and directly inhibit CaMKII activity $(10,11)$.

CaMKII is involved in numerous different physiological and pathological cellular processes $(12,13)$. Multiple studies have identified CaMKII to be important for cancer cell control by regulating cell cycle progression, cellular apoptosis and proliferation (8-11). For example, KN-62 and KN-93 induce cancer cell cycle arrest $(8,9)$. The endogenous inhibitors hCaMKIIN $\alpha$ and hCaMKIIN $\beta$ suppress tumor cell growth by inducing cell cycle arrest and apoptosis $(10,11)$. In addition, CaMKII has been reported to be required for prostate cancer cell survival (14). Accumulating evidence suggests that CaMKII is involved in the regulation of cell migration (15-19); specifically, it enhances vascular smooth muscle migration after injury and stress (15-17). CaMKII is also required for ghrelin-induced glioma cell migration (18) and ClC-3-induced glioma invasion (19), suggesting that CaMKII is associated with cancer cell migration and invasion. However, the function of CaMKII in gastric cancer cell metastasis remains to be elucidated.

The present study investigated the function of CaMKII in gastric cancer cell metastasis and the underlying molecular mechanisms.

\section{Materials and methods}

Reagents and cell culture. KN-62 and PDTC were purchased from Calbiochem (San Diego, CA, USA). Dimethylsulfoxide was purchased from Sigma-Aldrich (St. Louis, MO, USA). The primary antibodies against $\beta$-actin (sc-8432; mouse monoclonal IgG1), MMP-9 (sc-12759; mouse monoclonal IgG1), IKB $\alpha$ (sc-203; rabbit polyclonal IgG), phospho (p)-IKB $\alpha$ (sc-8404; mouse monoclonal IgG2b), CaMKII (sc-9035; rabbit polyclonal IgG) and p-CaMKII $\alpha$ (Thr 286) (sc-12886-R; rabbit polyclonal IgG) were obtained from Santa Cruz Biotechnology, Inc. (Santa Cruz, CA, USA). Four human gastric cancer cell lines (MKN28, GBC-SD, BGC-803 and SGC-7901) were obtained from the American Type Culture Collection (Manassas, VA, USA). The cells were cultured in RPMI-1640 (Invitrogen Life Technologies, Carlsbad, CA, USA) containing $10 \%$ fetal bovine serum (FBS) at $37^{\circ} \mathrm{C}$ in a $5 \% \mathrm{CO}_{2}$ atmosphere.

Reverse transcription-quantitative polymerase chain reaction (RT-qPCR) analysis of MMP9 mRNA expression. Total cellular RNA was extracted using TRIzol reagent (Invitrogen Life Technologies) according to manufacturer instructions. Single strand cDNA was synthesized from $2 \mathrm{mg}$ total RNA with the Superscript II system (Life Technologies, Rockville, MD, USA) using an oligo(dT)12-18 primer (Invitrogen Life Technologies). The primer sequences were as follows: 5'-TGTACCGCTATGGTTACACTCG-3' and 5'-GGCAGGGACAGTTGCTTCT-3' for human MMP9; and 5'-TGGAGAAAATCTGGCACCACACC-3' and 5'-GATGGGCACAGTGTGGGTGACCC-3' for actin (as a control gene). Primers were synthesized by Sangon Corporation (Shanghai, China). The synthesis of cDNA was checked by qRT-PCR using the actin primers. PCR consisted of denaturing $\left(95^{\circ} \mathrm{C}\right.$ for $\left.15 \mathrm{sec}\right)$, annealing $\left(56^{\circ} \mathrm{C}\right.$ for $\left.30 \mathrm{sec}\right)$, and extension $\left(72^{\circ} \mathrm{C}\right.$ for $30 \mathrm{sec}$ ) for 30 cycles using a PCR system (Applied Biosystems, Foster City, CA, USA).
Tissue processing and protein extraction. The surgically resected gastric cancer tissues were collected from 20 gastric cancer patients (including, 10 non-metastatic cancer tissues and 10 metastatic cancer tissues with lymph nodes or vessels) from the Department of Oncology at Changzheng Hospital, the Second Military Medical University (Shanghai, China). The samples were acquired following obtaining informed consent from the patients. All of the experimental procedures were approved by the Institute Research Ethics Committee at the Second Military Medical University. All of the fresh specimens were washed three times with phosphate-buffered saline (PBS) and dissected, and the protein was extracted from cell lysates with cell lysis buffer (Cell Signaling Technology, Inc., Boston, MA, USA) according to the manufacturer's instructions.

Western blot analysis. Protein concentration was measured by the Bicinchoninic Acid protein assay reagent kit (Pierce, Rockford, IL, USA). The protein $(50 \mu \mathrm{g})$ from gastric cancer cells and tissue samples were resolved with 10\% SDS-PAGE and subjected to western blot analysis. The blots were probed with the specific primary antibodies $(1: 1,000)$ followed by the appropriate horseradish peroxidase-conjugated secondary antibodies (1:2,000; Cell Signaling Technology Inc., Beverly, MA, USA). The bands were visualized with SuperSignal West Femto chemiluminescent reagents (Pierce Biotechnology, Inc., Rockford, IL, USA).

Constructof constitutivelyactive CaMKII and celltransfection. Constitutively active CaMKII expression plasmid was cloned with PCR cloning and mutation (H282 is mutated H282R). Flag-tagged expression vectors of $\mathrm{H} 282 \mathrm{R}$ were constructed and transfected into BGC-803 using Jetpei (Polyplus Transfection, Illkirch, France) according to the manufacturer's instructions. cDNA encoding constitutively active human CaMKII $\alpha$ (His282 mutated to Arg, H282R) was amplified by PCR. Primer were: 5'-GGCATCCCTGCATGGGCAGAC-3' and 5'-ACGGTGGAGCGGTGCGAGAT-3'. PCR was performed by denaturing the reaction mixture at $94^{\circ} \mathrm{C}$ for $2 \mathrm{~min}$, followed by 32 cycles $\left(1 \mathrm{~min}\right.$ at $94^{\circ} \mathrm{C}, 1 \mathrm{~min}$ at $58^{\circ} \mathrm{C}$ and $1 \mathrm{~min}$ at $72^{\circ} \mathrm{C}$ ). The amplification product was inserted into the Flag-tagged expression vectors (Invitrogen Life Technologies), and transfected into BGC 803 using Jetpei (Polyplus Transfection) according to the manufacturer's instructions.

Migration and invasion assay. Transwell polycarbonate membranes and Matrigel-coated invasion chambers (BD Biosciences, San Jose, CA, USA) were used to determine the effect of CaMKII on cell migration and invasion, respectively. The BGC-803 and SGC-7901 cells were starved with free medium, and $5 \times 10^{4}$ cells were suspended in RPMI-1640 medium with $\mathrm{KN}-62(10 \mu \mathrm{m})$ and added to the upper chamber. The lower chamber was filled with $500 \mu \mathrm{l}$ of media containing $10 \%$ FBS. Following $24 \mathrm{~h}$ culture, non-migrated or non-invasive cells were scraped from the upper side of the Transwell membrane filter inserts with a cotton-tipped swab. Migrated/invasive cells on the lower side were stained with crystal violet and counted. The number of migrated/invaded cells were counted in three independent high powered fields (x20) readings with a light microscope (DFC420C; Leica Microsystems, Wetzlar, Germany). 
A

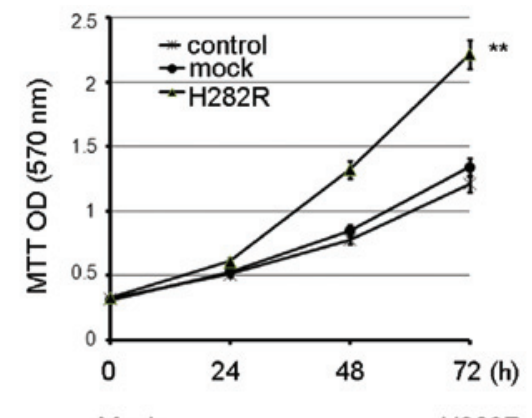

C

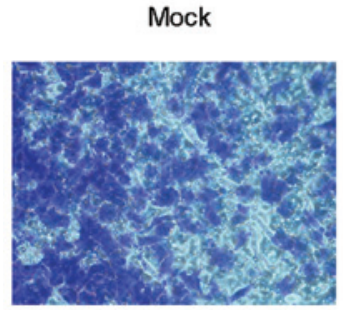

D

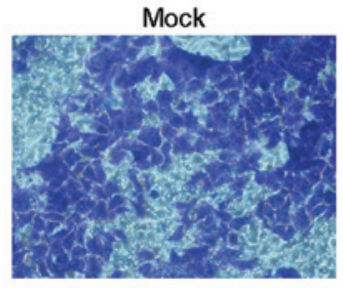

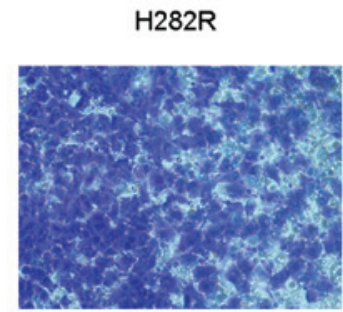

H282R

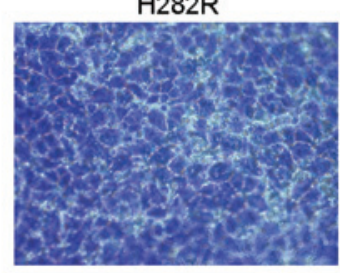

B
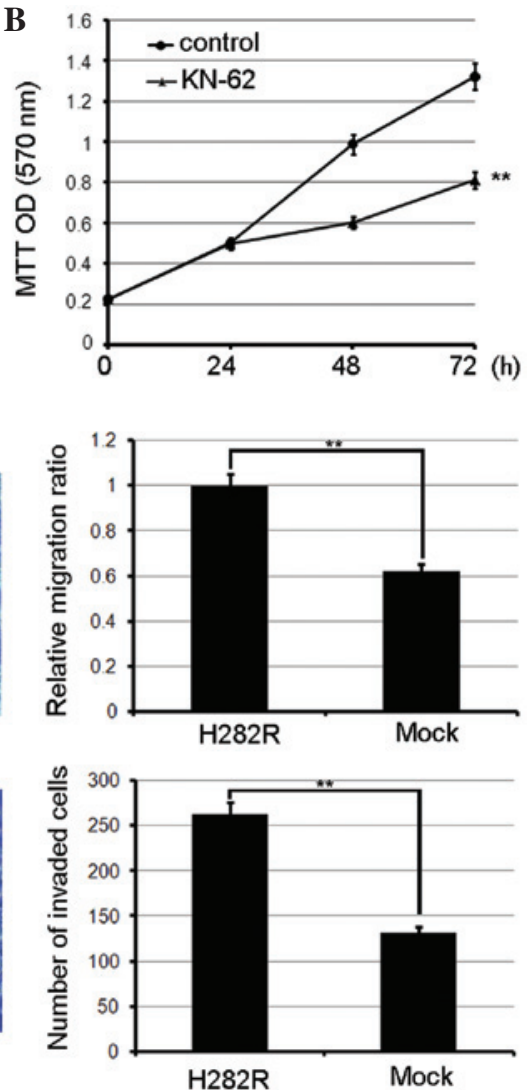

Figure 1. CaMKII promotes cell migration and invasion in gastric cancer cells. (A) BGC-803 cells were transfected with H282R expression vectors or mock vectors for $48 \mathrm{~h}$ and (B) BGC-803 cells were treated with KN-62 (10 $\mu \mathrm{m})$ for the indicated times. In vitro cell growth was measured using a 3-(4,5-dimethylthiazol-2-yl)-2,5-diphenyltetrazolium bromide assay. Data from the (C) transwell migration assays and (D) invasion assays in BGC-803 cells stably expressing H282R or the mock expression vector. Magnification, $x 20$. The cells were quantified with crystal violet staining. Data are expressed as the mean \pm standard deviation $(\mathrm{n}=4)$. Similar results were obtained in three independent experiments. ${ }^{* *} \mathrm{P}<0.01$, compared with mock. CaMKII, calcium/calmodulin-dependent protein kinase II; OD, optical density.

A

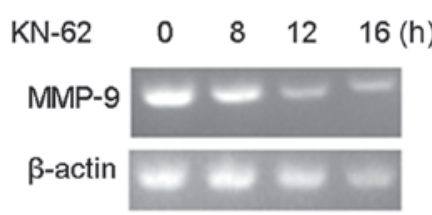

B

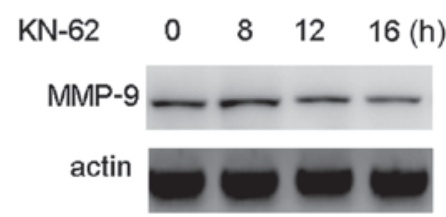

C

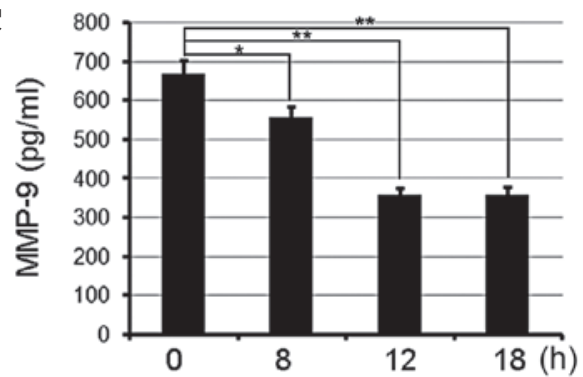

Figure 2. Inhibition of CaMKII activity suppresses MMP-9 expression and production. BGC-803 cells were treated with KN-62 (10 $\mu$ m) for the indicated time and (A) polymerase chain reaction analysis was utilized for detecting the MMP-9 mRNA expression. (B) Western blot analysis was utilized for identifying MMP-9 protein expression measured with the indicated antibodies. (C) ELISA was used to measure the MMP-9 production. Data are expressed as the mean \pm standard deviation $(\mathrm{n}=6)$. Similar results were obtained in three independent experiments. ${ }^{*} \mathrm{P}<0.05$ and ${ }^{* *} \mathrm{P}<0.01$. CaMKII, calcium/calmodulin-dependent protein kinase II; MMP-9, matrix metalloproteinase-9.

Measurement of MMP-9 production by ELISA. The production of MMP-9 in the culture supernatants was quantified with ELISA (R\&D Systems, Minneapolis, MN, USA) according to the manufacturer's instructions, as described previously (20).

Nuclear factor $(N F)-\kappa B$ activation assay. The cells were co-transfected with a mixture of $\mathrm{NF}-\kappa \mathrm{B}$ luciferase reporter plasmid, pRL-TK-Renilla-luciferase plasmid and the appropriate additional constructs or KN-62 for $24 \mathrm{~h}$. Total DNA was equalized with an empty control vector. Luciferase activity was measured with a dual-luciferase reporter assay system (Promega Corporation, Madison, WI, USA) according to the manufacturer's instructions. The data were normalized for transfection efficiency by measuring firefly luciferase activity and comparing it with that of Renilla luciferase.

Statistical analysis. Data are expressed as the mean \pm standard deviation and compared using Student's t-test. $\mathrm{P}<0.05$ was considered to indicate a statistically significant difference. 
A

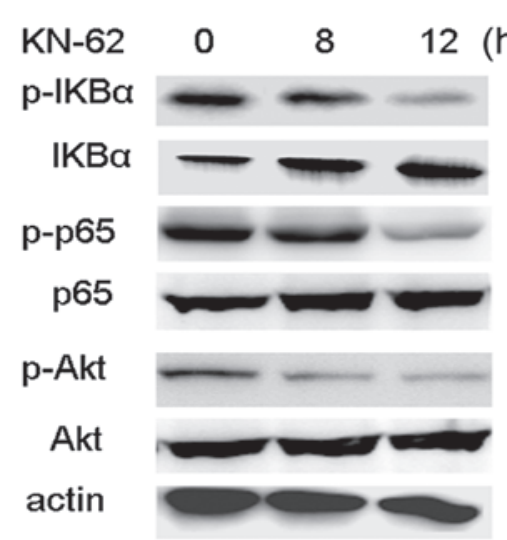

C

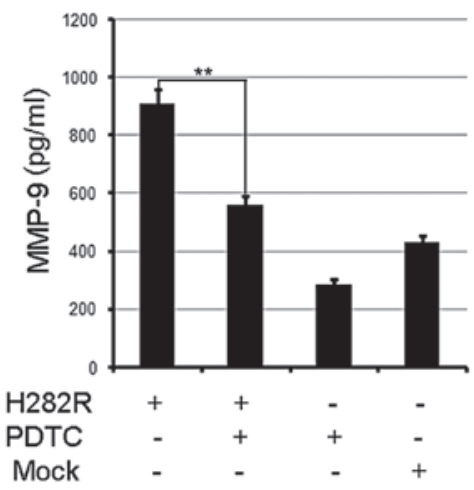

B

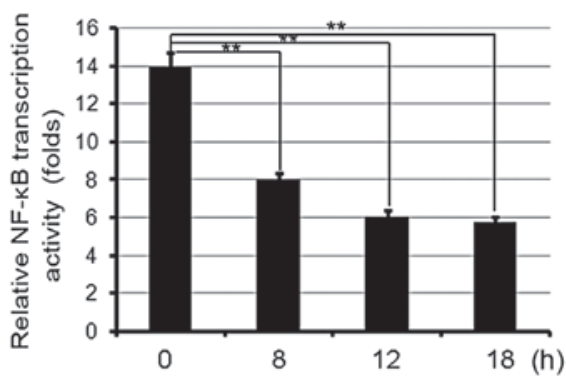

D

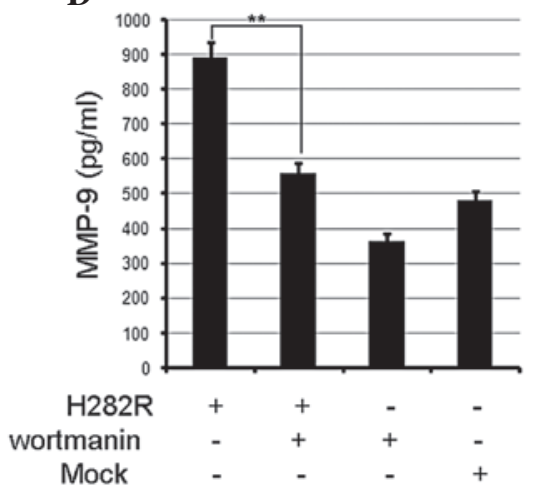

Figure 3. CaMKII-mediated NF-kB and Akt activation enhanced MMP-9 production in gastric cancer cells. (A) BGC-803 and SGC-7901 cells were treated with $\mathrm{KN}-62(10 \mu \mathrm{m})$ for $24 \mathrm{~h}$ and then analyzed with western blot analysis with the indicated antibodies. (B) BGC-803 cells were transfected with pGL3.5xNF- $\mathrm{kB}$ luciferase plasmid or pRL-TK-Renilla plasmid as a control plasmid, and KN-62 was added $(10 \mu \mathrm{m})$. Following $(24 \mathrm{~h})$ transfection, the luciferase activity was measured using a luciferase reporter assay kit. (C) BGC-803 cells were transfected with H282R plasmid for $24 \mathrm{~h}$, and then treated with PDTC (10 $\mu \mathrm{m}$ ) and (D) wortmanin for $24 \mathrm{~h}$. MMP-9 production was measured with ELISA. Data are expressed as the mean \pm standard deviation $(\mathrm{n}=6)$. Similar results were obtained in three independent experiments. ${ }^{* *} \mathrm{P}<0.01$. CaMKII, calcium/calmodulin-dependent protein kinase II; NF- $\mathrm{kB}$, nuclear factor $\kappa \mathrm{B}, \mathrm{MMP}-9$, matrix metalloproteinase-9.

A

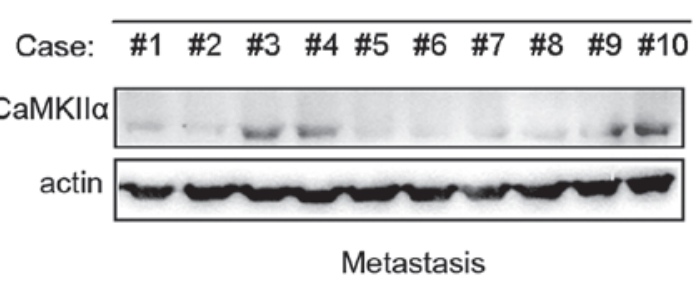

Case: \#1 \#2 \#3 \#4 \#5 \#6 \#7 \#8 \#9 \#10

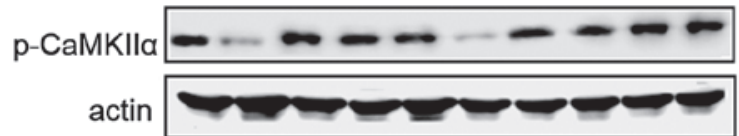

B

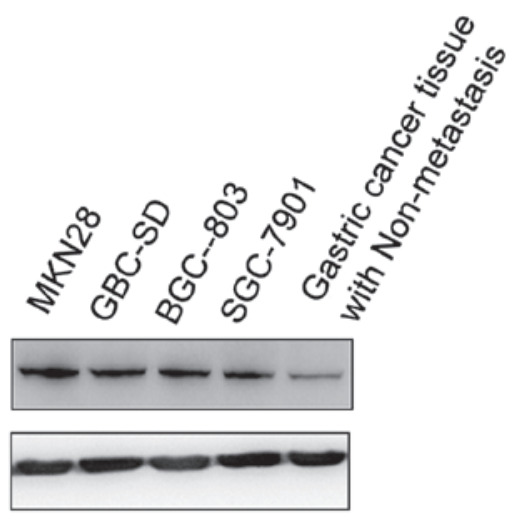

Figure 4. CaMKII activity in gastric cancer tissue and cell lines. CaMKII (Thr 286) phosphorylation in (A) gastric cancer tissues and (B) gastric cancer cell lines. Gastric cancer tissue protein and cells were extracted and quantified using a bicinchoninic aicd kit, and $50 \mu \mathrm{g}$ protein was separated with SDS-PAGE and the proteins were detected using antibodies. CaMKII, calcium/calmodulin-dependent protein kinase II.

\section{Results}

CaMKII promotes gastric cancer cell migration and invasion. The mechanisms underlying cancer metastasis involve multiple factors and the alteration of various genes. To investigate the role of CaMKII on the regulation of gastric cancer cells, constitutively active CaMKII (H282 mutated to R) expression plasmid with Flag-tagged H282R, was constructed by PCR. Firstly, when observing the effects of CaMKII on gastric cancer growth via a 3-(4,5-dimethylthiazol-2-yl)-2,5-diphenyltetrazolium bromide assay, it was noted that H282R overexpression accelerated BGC- 803 cell 
proliferation compared with the mock transfected cells. Also, the inhibition of CaMKII activity by KN-62 significantly suppressed cell growth compared with the control (Fig. 1A and B). Next, to assess the role of CaMKII in gastric cancer cell invasion and metastasis, it was observed that greater numbers of BGC-803 cells stably expressing H282R migrated to the opposite sides of the filters compared with the control cells treated with KN-62 (Fig. 1C). Similarly, greater numbers of BGC-803 cells stably expressing H282R invaded the matrigel compared with the control cells (Fig. 1D). Therefore, CaMKII was able to promote gastric cancer metastasis.

CaMKII enhances MMP-9 production of gastric cancer cells. MMP-9 is known to have a crucial role in cancer cell metastasis $(21,22)$, thus, it was investigated whether MMP-9 was involved in CaMKII-mediated promotion of migration and invasiveness. Firstly, the MMP-9 expression in KN-62-treated gastric cancer cells was measured and it was observed that the inhibition of CaMKII activity by KN-62 decreased MMP-9 expression in a time-dependent manner and peaked following treatment for $16 \mathrm{~h}$ as measured by PCR (Fig. 2A). Immunoblotting assays confirmed that KN-62 decreased the MMP-9 expression at the protein level (Fig. 2B). In addition, MMP-9 was released from $\mathrm{KN}$-62-treated cells according to ELISA. MMP-9 production was decreased in $\mathrm{KN}$-62-treated BGC-803 cells compared with the controls (Fig. 2C). Therefore, CaMKII inhibition suppressed MMP-9 expression and production.

CaMKII enhances $N F-\kappa B$ transcription and Akt activation, thereby promoting MMP-9 production. Several signaling pathways participate in cancer metastasis, including MAPK, phosphoinositide 3-phospate (PI3K)-Akt and NF- $\kappa$ B. CaMKII was recently demonstrated to be a central regulator of $\mathrm{NF}-\kappa \mathrm{B}$ activation in lymphocytes (23). To examine whether CaMKII affects $\mathrm{NF}-\kappa \mathrm{B}$ transcription activity in gastric cancer cells, phosphorylated IKB $\alpha$, total IKB $\alpha$ and active NF- $\kappa \mathrm{B}$ (p-p65) levels were measured by western blot analysis. As demonstrated in Fig. 3A, KN-62 decreased IKB $\alpha$ and p65 phosphorylation, and increased IKB $\alpha$ in BGC-803 cells. Using a luciferase reporter assay, it was identified that $\mathrm{NF}-\kappa \mathrm{B}$ transcription activation was inhibited by KN-62 (Fig. 3B). In addition, Akt activation was suppressed in KN-62-treated BGC-803 cells (Fig. 3A). Therefore, CaMKII increased NF- $\kappa \mathrm{B}$ transcription and Akt activation in gastric cancer cells.

$\mathrm{NF}-\kappa \mathrm{B}$ is a key transcription factor for MMP-9 expression in physiological and pathological conditions (24), it was therefore important to examine whether $N F-\kappa B$ is involved in CaMKII-mediated upregulation of MMP-9 expression. It was identified that the overexpression of H282R increased MMP-9 production, and that PDTC, a specific NF- $\kappa \mathrm{B}$ inhibitor, partly inhibited the H282R-mediated upregulation of MPP-9 production (Fig. 3C). It was also investigated whether Akt is involved in CaMKII-mediated upregulation of MMP-9 expression, it was identified that wortmanin, a specific Akt inhibitor, decreased H282R-mediated upregulation of MPP-9 production (Fig. 3D). Therefore, CaMKII upregulated MMP-9 in gastric cancer cells and this was dependent on $\mathrm{NF}-\kappa \mathrm{B}$ and Akt activation.
CaMKII activity was enhanced in metastatic gastric cancer. Next, the activation of CaMKII in gastric cancer tissues was observed. It was noted that $70 \%$ of the cases of gastric cancer with metastasis, including lymph node and/or lymphatic vessel metastasis, had higher CaMKII phosphorylation (at Thr286) compared with $20 \%$ of the cases of non-metastatic cancer (Fig. 4A). Next, CaMKII phosphorylation in diverse gastric cancer cell lines, which have greater capability of invasiveness was examined. The CaMKII phosphorylation was increased in four higher metastatic gastric cancer cell lines (MNK28, GBC-SD, BGC-803 and SGC-7901; Fig. 4B). These findings further confirm that CaMKII may be involved in gastric cancer metastasis and therefore targeting this kinase may represent a strategy for preventing gastric cancer metastasis.

\section{Discussion}

Cancer metastasis is an obstacle to cancer therapy and a leading cause of mortality for gastric cancer patients (2). To overcome and improve treatment outcomes, understanding the biological mechanisms of gastric cancer metastasis is required. To the best of our knowledge, the present study demonstrates for the first time that CaMKII promotes gastric cancer metastasis by upregulating NF- $\mathrm{B} / \mathrm{Akt}$-dependent MMP-9 production.

To investigate the molecular mechanisms underlying pro-gastric cancer metastatic properties of CaMKII, MMP-9, a classic metastatic-prompting gene implicated in numerous types of human cancer for its ability to cleave various extracellular matrix molecules, was examined $(25,26)$. CaMKII has been reported to regulate MMP-9 activity, as conferred by the evidence that CaMKII promotes MMP-9 expression in cardiomyocytes (27) and promotes vascular smooth muscle migration via the regulation of MMP-9 activity (15). In the present study, inhibition of CaMKII decreased MMP-9 expression and production, and the overexpression of $\mathrm{H} 282 \mathrm{R}$ or constitutively activate CaMKII, increased MMP-9 production, which was consistent with the results of previous studies $(15,27)$. Furthermore, CaMKII activity was observed to be increased in samples of metastatic gastric cancer, which also confirms the pro-metastatic biological function of CaMKII. Therefore, CaMKII enhances gastric cancer cell metastasis by increasing MMP-9 expression and production.

MMP-9 production is regulated by multiple signaling pathways (28-30). Previous studies have demonstrated that NF- $\kappa$ B is a key regulator of MMP-9 (31). The present data indicate that CaMKII upregulated MMP-9 expression, and inhibition of NF- $\kappa \mathrm{B}$ activation eliminated CaMKII-mediated MMP-9 production. This suggests that CaMKII increased MMP-9 expression by enhancing $\mathrm{NF}-\kappa \mathrm{B}$ activation. A binding site for $\mathrm{NF}-\kappa \mathrm{B}$ has been reported to be the promoter of the MMP-9 gene, contributing to MMP-9 expression (32), a concept that supports the present findings that NF- $\kappa \mathrm{B}$-dependent CaMKII-mediated MMP-9 expression patterns. In addition, these data demonstrate that CaMKII-mediated MMP-9 expression was partly dependent on Akt activation. However, Further studies are required to elucidate the details of this regulatory mechanism

In conclusion, CaMKII enhanced gastric cancer cell metastasis by upregulating NF- $\mathrm{B}-/$ Akt-dependent MMP-9 production. To the best of our knowledge, this is the first study 
that demonstrates that CaMKII is able to regulate gastric cancer metastasis. These data provide the theoretical basis for the development of CaMKII inhibitors to treat gastric cancer metastasis.

\section{Acknowledgements}

The authors would like to thank Dr Guanzhen Yu (Department of Pathology, Changzheng Hospital, Shanghai, China) for providing the gastric cancer specimens and technique assistance. The authors would also like to thank the Letpub group for providing language aid. This study was supported by a grants from the National Natural Science Foundation of China (grant no. 31070789).

\section{References}

1. Jemal A, Siegel R, Ward E, Hao Y, Xu J, Murray T and Thun MJ: Cancer statistics. CA Cancer J Clin 58: 71-96, 2008.

2. Ahmad SA, Berman RS and Ellis LM: Biology of colorectal liver metastases. Surg Oncol Clin N Am 12: 135-150, 2003.

3. Cairns RA, Khokha R and Hill RP: Molecular mechanisms of tumor invasion and metastasis: an integrated view. Curr Mol Med 3: 659-671, 2003.

4. Hudmon A and Schulman $\mathrm{H}$ : Neuronal $\mathrm{Ca}^{2+} / \mathrm{calm}_{\text {modulin-dependent }}$ protein kinase II: the role of structure and autoregulation in cellular function. Annu Rev Biochem 71: 473-510, 2002.

5. Erickson JR, He BJ, Grumbach IM and Anderson ME: CaMKII in the cardiovascular system: sensing redox states. Physiol Rev 91: 889-915, 2011.

6. Braun AP and Schulman H: The multifunctional calcium/calmodulin-dependent protein kinase: from form to function. Annu Rev Physiol 57: 417-445, 1995.

7. Coultrap SJ, Buard I, Kulbe JR, Dell'Acqua ML and Bayer KU: CaMKII autonomy is substrate-dependent and further stimulated by $\mathrm{Ca}^{2+}$ calmodulin. J Biol Chem 285: 17930-17937, 2010.

8. Ducibella T, Schultz RM and Ozil JP: Role of calcium signals in early development. Semin Stem Cell Dev Biol 17: 324-332, 2006.

9. Zayzafoon M: Calcium/calmodulin signaling controls osteoblast growth and differentiation. J Cell Biochem 97: 56-70, 2006.

10. Wang C, Li N, Liu X, Zheng Y and Cao X: A novel endogenous human CaMKII inhibitory protein suppresses tumor growth by inducing cell cycle arrest via p27 stabilization. J Biol Chem 283 : $11565-11574,2008$.

11. Ma S, Yang Y, Wang C, et al: Endogenous human CaMKII inhibitory protein suppresses tumor growth by inducing cell cycle arrest and apoptosis through down-regulation of the phosphatidylinositide 3-kinase/Akt/HDM2 pathway. J Biol Chem 284: 24773-24782, 2009.

12. Gardoni F, Mauceri D, Marcello E, Sala C, Di Luca M and Jeromin A: SAP97 directs the localization of Kv4.2 to spines in hippocampal neurons: regulation by CaMKII. J Biol Chem 282: 28691-28699, 2007.

13. Erickson JR, Joiner ML, Guan X, Kutschke W, Yang J, Oddis CV, Bartlett RK, Lowe JS, O'Donnell SE, Aykin-Burns N, et al: A dynamic pathway for calcium-independent activation of CaMKII by methionine oxidation. Cell 133: 462-474, 2008.

14. Rokhlin OW, Taghiyev AF, Bayer KU, Bumcrot D, Koteliansk VE, Glover RA and Cohen MB: Calcium/calmodulin-dependent kinase II plays an important role in prostate cancer cell survival. Cancer Biol Ther 6: 732-742, 2007.

15. Scott JA, Xie L, Li H, Li W, He JB, Sanders PN, Carter AB, Backs J, Anderson ME and Grumbach IM: The multifunctional $\mathrm{Ca}^{2+} /$ calmodulin-dependent kinase II regulates vascular smooth muscle migration through matrix metalloproteinase 9. Am J Physiol Heart Circ Physiol 302: H1953-H1964, 2012.
16. Mercure MZ, Ginnan R and Singer HA: CaM kinase II delta2-dependent regulation of vascular smooth muscle cell polarization and migration. Am J Physiol Cell Physiol 294: C1465-C1475, 2008

17. Yang $M$ and Kahn AM: Insulin-inhibited and stimulated cultured vascular smooth muscle cell migration are related to divergent effects on protein phosphatase-2A and autonomous calcium/calmodulin-dependent protein kinase II. Atherosclerosis 196: 227-233, 2008.

18. Chen JH, Huang SM, Chen CC, Tsai CF, Yeh WL, Chou SJ, Hsieh WT and Lu DY: Ghrelin induces cell migration through GHS-R, CaMKII, AMPK, and NF- $\mathrm{BB}$ signaling pathway in glioma cells. J Cell Biochem 112: 2931-2941, 2011.

19. Cuddapah VA and Sontheimer H: Molecular interaction and functional regulation of $\mathrm{ClC}-3$ by $\mathrm{Ca}^{2+} /$ calmodulin-dependent protein kinase II (CaMKII) in human malignant glioma. J Biol Chem 285: 11188-11196, 2010.

20. Asahi M, Asahi K, Jung JC, del Zoppo GJ, Fini ME and Lo EH: Role for matrix metalloproteinase 9 after focal cerebral ischemia: effects of gene knockout and enzyme inhibition with BB-94. J Cereb Blood Flow Metab 20: 1681-1689, 2000.

21. Galis ZS, Sukhova GK, Kranzhöfer R, Clark S and Libby P: Macrophage foam cells from experimental atheroma constitutively produce matrix-degrading proteinase. Proc Natl Acad Sci USA 92: 402-406, 1995.

22. Klein G, Vellenga E, Fraaije MW, Kamps WA and de Bont ES: The possible role of matrixmetalloproteinase (MMP)-2 and MMP-9 in cancer, e.g. acute leukemia. Crit Rev Oncol Hematol 50: 87-100, 2004.

23. Ishiguro K, Green T, Rapley J, Wachtel H, Giallourakis $\mathrm{C}$, Landry A, Cao Z, Lu N, Takafumi A, Goto H, Daly MJ and Xavier RJ: $\mathrm{Ca}^{2+} /$ calmodulin-dependent protein kinase II is a modulator of CARMA1-mediated NF-kappaB activation. Mol Cell Biol 26: 5497-5508, 2006.

24. Chou YC, Sheu JR, Chung CL, Chen CY, Lin FL, Hsu MJ, Kuo YH and Hsiao G: Nuclear-targeted inhibition of NF-kappaB on MMP-9 production by N-2-(4-bromophenyl) ethyl caffeamide in human monocytic cells. Chem Biol Interact 184: 403-412, 2010.

25. Deryugina EI and Quigley JP: Matrix metalloproteinases and tumor metastasis. Cancer Metastasis Rev 25: 9-34, 2006.

26. Egeblad M and Werb Z: New functions for the matrix metalloproteinases in cancer progression. Nat Rev Cancer 2: 161-174, 2002.

27. He BJ, JoinerML, Singh MV, et al: Oxidation of CaMKII determines the cardiotoxic effects of aldosterone. Nat Med 17: 1610-1618, 2011.

28. Cheng CY, Hsieh HL, Hsiao LD and Yang CM $\mathrm{PI} 3-\mathrm{K} / \mathrm{Akt} / \mathrm{JNK} / \mathrm{NF}-\kappa \mathrm{B}$ is essential for MMP-9 expression and outgrowth in human limbal epithelial cells on intact amniotic membrane. Stem Cell Res 9: 9-23, 2012.

29. Liang KC, Lee CW, Lin WN, Lin CC, Wu CB, Luo SF and Yang CM: Interleukin-1beta induces MMP-9 expression via p42/p44 MAPK, p38 MAPK, JNK, and nuclear factor-kappaB signaling pathways in human tracheal smooth muscle cells. J Cell Physiol 211: 759-770, 2007.

30. Bond M, Chase AJ, Baker AH and Newby AC: Inhibition of transcription factor NF-kappaB reduces matrix metalloproteinase-1, -3 and -9 production by vascular smooth muscle cells. Cardiovasc Res 50: 556-565, 2001.

31. Bond M, Fabunmi RP, Baker AH and Newby AC: Synergistic upregulation of metalloproteinase- 9 by growth factors and inflammatory cytokines: an absolute requirement for transcription factor NF-kappa B. FEBS Lett 435: 29-34, 1998.

32. Rhee JW, Lee KW, Kim D, Lee Y,Jeon OH, Kwon HJ and Kim DS: NF-kappaB-dependent regulation of matrix metalloproteinase-9 gene expression by lipopolysaccharide in a macrophage cell line RAW 264.7. J Biochem Mol Biol 40: 88-94, 2007. 